\title{
Digital visual schedule and training system for centre of autistic children
}

\begin{abstract}
Research indicated that there is no proven cure for autism sufferers. Usually, implementing the appropriate treatment and education can eventually help the autism person to be integrated into their community. However, the conventional visual schedule and training system that depending on physical tool and toy bringing the difficulty on changing or update the picture, text and current using tool. Therefore, Digital Visual Schedule and Training System (DVST System) is developed as a user- friendly, interactive and flexibility system for children with autism. The inconveniency of traditional training program that depending on physical tool or multiple application software is improved by DVST system that provides a complete set of features and functions for the therapist and autistic children to carry out the administration work (for therapist-Server) as well as training program (for autistic childrenClient) in a single application.
\end{abstract}

Keyword: Autism; Digital visual schedule; Education; Picture exchange communication system; Training 